\title{
FESTA DE NOSSA SENHORA DA ABADIA - UM GIRO PELO TERRITÓRIO
}

\author{
Marlene Flauzina Oliveira ${ }^{1}$
}

Resumo: Pretende-se com esse trabalho analisar o território abarcado pela festa de Nossa Senhora da Abadia em Jataí/GO. A compreensão da centenária festa pelos pressupostos: tradição e territorialidade advém porque ambos transmitem saberes e fazeres culturais por meio das relações sociais no território, ao serem materializadas e simbolicamente representadas. Para compreensão desta festa popular utilizou-se a metodologia qualitativa para explicar as relações percebidas entre cultura, tradição, festa popular, território e identidade. A base teórica foi fundamental para sustentar as informações coletadas e registradas in loco. A espacialidade e a temporalidade da festa resultam de solidariedade e de reciprocidade, por meio das práticas sociais e dos rituais sagrados e profanos. A religiosidade faz de seus devotos propagadores da fé, da tradição festiva e cultural na "Região da Onça".

Palavras-chave: Festa popular; Territorialidade; Identidades.

\section{OUR LADY OF ABADIA'S FEST - A TURN IN THE TERRITORY}

Abstract: This work is intended to analyze the territory covered by Our Lady of Abadia's Fest in Jataí/GO. The centenary's fest comprehension based on: tradition and territoriality comes because both transmit knowledge and cultural doings by social relations in the territory when materialized and symbolically represented. For comprehension of this popular fest we used a qualitative methodology to explain the detected relations between culture, tradition, popular fest, territory and identity. The theoretical basis was essential to sustain the collected and recorded in loco information. The spatiality and temporality of the Fest comes from solidarity and reciprocity by means of the social practices and the sacred and profane rituals. The religiosity makes of its devotees propagators of the faith and of the cultural and festive tradition in the "Onça's Area".

Key Words: Popular fest; Territoriality; Identities.

\section{FIESTA DE NUESTRA SEÑORA DE ABADIA - UN GIRO POR EL TERRITORIO}

Resumen: Se pretende con este trabajo analizar el territorio abarcado por la fiesta de Nuestra Señora de Abadia en Jataí/GO. La comprensión de la fiesta centenaria: tradición y territorialidad adviene por ambos transmitir saberes y haceres culturales por medio de las relaciones sociales en el territorio, al ser materializadas y simbólicamente representadas. Para la comprension de esta fiesta se utilisó la metodologia cualitativa para explicar las relaciones que se percibe entre cultura, tradición, fiesta popular, territorio e identidad. La base teorica fue fundamental para sostener las informaciones colectadas y registradas in loco. La espacialidad y la temporalidad de la fiesta resultan de la solidaridad y reprocidad por medio

\footnotetext{
${ }^{1}$ Geográfa. Universidade Federal de Goiás-IESA. E-mail: mflauzina@hotmail.com. Atualmente doutoranda pelo Programa de Pós-Graduação em Geografia - Universidade Federal da Grande Dourados/MS.

Artigo produzido para a disciplina: Identidades, território e territorialidades, ministrada pela Profa. Dra. Maria Geralda de Almeida. Programa de Pós-Graduação em Geografia/IESA/UFG. Em 2015. E-mail: mgdealmeida@gmail.com
} 
de las practicas sociales y de los rituales sagrados y profanos. La religiosid hace de sus devotos propagadores de la fe, la tradicion festiva y cultural en la "Región de la Onça".

Palabras clave: Fiesta popular; Territorialidad; Identidad.

\section{Introdução}

O município de Jataí/GO, se destaca na economia brasileira por meio de algumas atividades: a pecuária, monoculturas de soja, milho, sorgo e pelo setor sucroenergético. Silva 2011, aponta que

No ano de 2009, o município de Jataí foi o $5^{\circ}$ maior produtor nacional de milho, alcançando 537 milhões de toneladas; foi também o $11^{\circ}$ maior produtor de soja, com 624 milhões de toneladas; e possuía, nesse mesmo ano um rebanho bovino de 330 mil cabeças (IBGE, 2010) (SILVA, 2011, p. 129130).

Neste mesmo contexto Silva (2011, p. 132), afirma que "no ano de 2009, o município plantou 30 mil hectares de sorgo, além de contar 2.100 mil frangos (IBGE, 2010)." E no ano de 2010, em relação a produção do setor sucroenergético, “a produtividade alcançou 132 ton./ha. (CONAB-GO, 2011) [...] rendimento muito superior à média nacional" (SILVA, 2011, p. 141).

Esse processo econômico moderno que se desenvolve no município ocasiona algumas mudanças espaciais, tais como sociais, culturais e econômicas à comunidade jataiense. Estas mudanças influenciam em alguns pressupostos como: território, tempo, religiosidade, paisagem, sociabilidades, o modo de produzir, as técnicas de trabalho, o modo de fazer e saberes tradicionais.

Neste contexto de práticas econômicas e tecnológicas como a agricultura em grande escala, pecuária de maneira extensiva, o setor sucroenergético com a expansão do cultivo da cana-de-açúcar, se encontram traços fortíssimos da cultura popular. Como a culinária, os dizeres regionais, as crendices, religiosidades rústicas, os fazeres tradicionais representados nas vivências e experiências da comunidade jataiense. Machado (2002, p. 335), descreve que a cultura popular:

são todas aquelas práticas e representações culturais vivenciadas no cotidiano de atores sociais específicos, distantes do racionalismo científico, como forma de recriação do seu universo: crenças, hábitos, costumes, conhecimento. 
As expressões culturais apresentam em suas práticas elementos visíveis, bem como as invisibilidades e intangibilidades que buscaremos compreender em uma festividade com ações místicas e concretas. A festa escolhida é a celebração à Nossa Senhora da Abadia também conhecida como a Festa da Onça. Segundo relatos orais a manifestação acontece aproximadamente há 130 anos, em um lugar popularmente conhecido como "Região da Onça" ${ }^{2}$. Esta região é situada aproximadamente $30 \mathrm{~km}$ do perímetro urbano do município de Jataí/GO.

A festividade apresenta signos, rituais sagrados e profanos, aspectos do religioso rústico, atividades do cotidiano local e regional, relação histórica e relações sociais. Estes elementos estão presentes em todas as atividades que compõem a festa. Para esta festa abordaremos teoricamente o espaço onde se realiza, compreendendo, como os indivíduos instituem, utilizam e valorizam o território.

O objetivo deste texto é interpretar a festa de Nossa Senhora da Abadia, portadora de relações sociais que são responsáveis pela organização espacial. Compreender por meio da folia a formação de um território religioso durante seu giro ${ }^{3}$, na "Região da Onça". Ou seja, no tempo-espaço da festividade a mobilidade geográfica da folia gera um território convergido pelos sentimentos, sentidos, cores, formas, cheiros, sons e identidades.

Território esse concebido por meio das memórias e materialização dos ritos e símbolos do qual se permite pela geografia reproduzir este espaço. A partir de então, identificar as prováveis identidades por meio de sujeitos de uma região que, tradicionalmente, realizam a centenária festa de Nossa Senhora da Abadia.

Justifica-se a compreensão da festa de Nossa Senhora da Abadia pelo pressuposto tradição, que assume a função de transmitir o conhecimento por meio das atividades descritas pela oralidade e memorialidades coletivas. E, pela territorialidade do sagrado/profano no seu tempo. No entanto, a tradição e a territorialidade são procedimentos que transmitem saberes e fazeres culturais por meio das relações sociais no território ao ser materializadas, e simbolicamente representadas pelas relações sociais. Tradição e territorialidade produzem ritualmente o espaço em que atuam.

A festa de Nossa Senhora da Abadia é uma atividade coletiva, e necessita de um público envolvido na sua produção e em sua comemoração. Assim, os signos são retratados e

\footnotetext{
${ }^{2}$ A Região da Onça aqui não se trata de uma categoria cientificamente estudada na Geografia, mas, a forma popularmente conhecida do lugar.

${ }^{3}$ Giro: trajeto percorrido pela folia no tempo da festa.
} 
codificados por seus representantes (foliões, festeiros, devotos). A festa passa ser o lugar dos tipos, sons, cores, cheiros, reprodução dos rituais, da religiosidade, das memórias que viabilizam no seu tempo a transmissão de saberes. Para Amaral (1998, p. 52)

a festa é uma das vias privilegiadas no estabelecimento de mediações da humanidade. Ela busca recuperar a imanência entre criador e criaturas, natureza e cultura, tempo e eternidade, vida e morte, ser e não ser. A presença da música, alimentação, dança, mitos e máscaras atesta com veemência esta proposição. A festa é ainda mediadora entre os anseios individuais e os coletivos, mito e história, fantasia e realidade, passado e presente, presente e futuro, nós e os outros, por isso mesmo revelando e exaltando as contradições impostas à vida humana pela dicotomia natureza e cultura, mediando ainda os encontros culturais e absorvendo, digerindo e transformando em pontes os opostos tidos como inconciliáveis.

Durante sua celebração a vida social se torna pública e a festa se torna território disputado por diferentes identidades ou então se torna território de um grupo social. Mas, o público da festa que se torna também coletivo e heterogêneo participa da festa com o intuito comum a todos, expressar seus sentimentos e se identificar. Conforme Maia (1999, p. 197) "participar traduz, em efeito, um movimento intencional de "ir-ao-encontro-do-outro"” a participação na festa em evidência, também significa praticar a fé e a devoção.

Para compreendermos esta festa popular buscamos na geografia cultural o cunho epistemológico/metodológico capaz de explicar como se dão as identidades humanas individuais e coletivas no espaço percebido. Usamos abordagens qualitativas para analises das relações entre cultura, tradição, festa popular, território e identidade. Desta forma, foi necessário manter um diálogo entre autores que apresentam discussão sobre esses eixos. A base teórica foi fundamental para sustentar as informações coletadas in loco. Bem como, os registros das práticas por meio da observação, das entrevistas gravadas, transcrição das entrevistas, fotografias, anotações no caderno de campo, a história oral, e da fundamentação em referenciais teóricos como, livros, artigos, teses e dissertações.

\section{A festa: um elemento da coesão rural}

Em acordo com Hall (1997, p. 70)

todo meio de representação - escrita, pintura, desenho, fotografia, simbolização através da arte ou dos sistemas de telecomunicação - deve traduzir seu objeto em dimensões espaciais e temporais. 
É nessa perspectiva que também trataremos das dimensões cultural, religiosa, e política do território envolvido pela festa de Nossa Senhora da Abadia. E compreender ao mesmo tempo as representações simbólicas nele presentes.

O território é um produto do espaço envolvido pelas relações sociais, e sua apropriação acontece de forma afetiva e efetiva (Saquet; Gagliotto, 2009). O território por ser um lugar das relações sociais, condiz com a festa em estudo por evidenciar uma rede social, bem como as vivências no tempo da festa. Em relação ao tempo da festa, Muñoz (2006, p. 236) em seu estudo sobre o tempo no território urbano aponta que:

la percepción y contenido cultural del tempo también varían según como las personas hagan uso del mismos $\mathrm{y}$, en ese sentido, el tiempo establece diferencias claras entre los habitantes de un espacio concreto.

Trazendo essa citação para o contexto da festa podemos relacionar com o tempo aproveitado pelos diferentes sujeitos durante sua realização. O tempo da festa é o tempo de festejar a santa, de agradecer, de pagar e fazer promessas, do giro da folia, de doar emolas e serviços. Também é o tempo de rezas, cânticos religiosos, de rodas de viola, de fotografar, de dançar, de beber, das comilanças, dos jogos de mesa, de brincadeiras das crianças, dos grupos de adolescentes, das "gentes de fora", de ajuda mútua dos parentes, do compadrio, da vizinhança, dos namoros e o tempo das Intergerações.

Para entender o contexto desta festa no território no qual se realiza, elucidaremos um importante evento - a folia, a mesma nos permite estuda-la por vários vieses. Mas, antes são necessárias algumas informações importantes como o histórico do surgimento da festa. Segundo relatos orais dos participantes, a devoção a Nossa Senhora da Abadia surge por conta dos conflitos sangrentos entre índios e não índios na região. Em um desses ataques, quase toda uma família que morava ali, foi dizimada por indígenas. Diante desse fato, uma devota pede a Nossa Senhora da Abadia para afugentar os índios daquela região, e em agradecimento faria um jantar e rezaria um terço todos os anos em seu dia.

Para os participantes surge a partir desse momento um compromisso religioso e moral com a santa. Por meio da demonstração de fé na padroeira acontece uma troca simbólica de interesses, no qual recebem dela a proteção firmada no voto inicial e as bênçãos em seus votos particulares, e em troca pagam a promessa feita por meio da realização da festa 
e da reza do terço. Os participantes também firmam o compromisso por medo de uma revolta ou castigo vindos da santa. Afirma Rosendahl (2002) que:

Os santos são representações fundamentais do catolicismo popular, como seres pessoais e espirituais dotados de poderes sobrenaturais. [...] Os santos estão ao alcance de qualquer fiel sem a intervenção de especialistas eclesiásticos (ROSENDAHL, 2002, p. 72).

A promessa aparece neste contexto como uma prática religiosa do catolicismo popular, é uma forma do crente se sentir livre de alguma ameaça que foge de seu poder de resolução, ou seja, o alivio virá pelos poderes divinos. E a promessa permite essa relação direta do devoto com a santa.

No entanto, festas religiosas populares geralmente atraem uma quantidade grande de participantes sendo eles devotos ou não do padroeiro. Para os devotos esses manifestos sagrados/profanos, tem como valor central o santo. É o momento do contato imaginário e direto com o sagrado.

Conforme Oliveira (2012), os relatos orais dos participantes da festa e dos moradores da Região da Onça, a devoção à padroeira inicia-se por volta de 1882 aproximadamente. Desde então a festa foi se estruturando até o formato atual. 15 de agosto é o dia da santa, mas, comemora-se no dia 14 porque no seu dia os devotos consagram à padroeira.

Em seguida, uma breve descrição dos eventos que compõem a festividade, e, posteriormente, algumas atividades serão descritas com mais detalhes. O primeiro evento da festa acontece em meados de julho, quando se realiza a "saída da folia" é o momento onde os foliões se reúnem para sair para o giro. Neste, acontecem rituais sagrados e muitas diversões também.

"O giro da folia" é o momento em que os foliões percorrem um trajeto pré-definido, levando a imagem de Nossa Senhora da Abadia em uma bandeira. O giro antecede a festa e garante o seu custeio por meio das esmolas (dinheiro e prendas), recebidas durante sua realização às visitas nas residências durante o caminho.

O "dia da festa" esse sim é o momento para pagar o voto feito a Nossa Senhora da Abadia. Neste dia acontecem eventos para celebrar à santa e, também, da confraternização, dos encontros, das emoções. Pela manhã a alvorada da festa dá-se com a chegada dos participantes, o ritual sagrado inicia-se com a "chegada da bandeira ou da santa", trazida pelos foliões. Logo após tem se o farto e gratuito "almoço", e na sequencia, realiza-se o "leilão" 
para angariar recursos para custear os gastos da festa, o "jantar" também gratuito e com muita fartura.

A "reza do terço" ocorre com a participação coletiva e respeito dos devotos, é um dos momentos ápice da festa. Geralmente a reza é realizada por mulheres acompanhadas pela família do festeiro, dos foliões e dos demais devotos, logo após tem se "a queima da fogueira", que simboliza a vela acessa para a iluminar o mastro e para aquecer a noite fria de inverno. O "levantamento do mastro" acontece para hastear a bandeira da santa acompanhado pelas cantigas da folia. "O sorteio" neste ato são reveladas as próximas funções dos devotos para a futura festa, e também o próximo festeiro. A festividade se conclui com "o baile", que adentra a madrugada. Assim, compreendemos que os rituais sagrados e profanos neste dia, alternam e se completam, de modo a caracterizar a festa para padroeira.

\section{Folia de Nossa Senhora da Abadia - território do sagrado e do profano}

O catolicismo popular na Região da Onça desde a promessa inicial (re)cria o espaço místico, por meio dos rituais sagrados todos os anos no tempo da festa. Neste contexto, o território é usado pela religião popular, pelas relações e práticas sociais em um determinado período. Haesbaert (2009) define o território:

a partir de uma abordagem sobre o espaço que prioriza ou que coloca seu foco, no interior dessa dimensão espacial, n-a "dimensão", ou melhor, n-as problemáticas de caráter político ou que envolvem a manifestação e/ou realização das relações de poder em suas múltiplas esferas (HAESBAERT, 2009. p. 105).

A dimensão ritualística do festejo a Nossa Senhora da Abadia, se materializa no território por meio das práticas sociais, em espaços pré-determinados. Inicia-se com um ritual sagrado/profano na casa do guardião da bandeira e dos instrumentos musicais, este ritual é conhecido como a "saída da folia". É realizado um farto jantar, produzido pelos donos da casa, com ajuda dos vizinhos, parentes, compadrios e amigos. Na sequência segue, com a reza do terço e posteriormente o momento de descontração com a roda de viola, danças e consumo de bebidas pela noite toda.

No dia seguinte a folia em cantorias pede aos moradores a bandeira da santa para sair para o giro, canta para todos os participantes do local que quiserem segurar a bandeira, doar algo, dinheiro, fixar objetos na bandeira, fazer pedidos e pagar promessas. 
A materialização segue com as atividades da folia de Nossa Senhora da Abadia, que percorre o espaço dando formas e atribuindo sua função de viajores ao trajeto, com a bandeira da santa. Faz visitas e ganha pousos nas propriedades que geralmente tem jantar e rezas. Estas ações atraem outros participantes para estas propriedades. Finaliza se o momento da celebração na casa do festeiro, com a majestosa festa dedicada à santa.

A folia é um agente modelador do território religioso na "Região da Onça", o elabora por meio de seus valores e crenças. Desempenha no seu tempo ações particulares que elevam a fé dos religiosos bem como os aproximam do sagrado, dessa forma o devoto tem o contato direto com a santa, reforçando sua crença na padroeira. O profano também e reforçado por meio das confraternizações que acontecem em algumas moradias, durante o trajeto. "Tudo é, ao mesmo tempo, expressão da legítima alegria e fé autêntica na padroeira." (ROSENDAHL, 2009, p. 63). A partir dessa relação cultural, social e espacial surge a territorialidade política e religiosa no espaço, reforçando o sentimento de pertencimento resultando na perpetuação da tradição centenária.

Para melhor compreensão e visualização do território e sua territorialização por meio das atividades da folia da festa de Nossa Senhora da Abadia, veja o mapa 01 com o giro do ano de 2011.

Mapa 01 - Giro da folia de Nossa Senhora da Abadia 


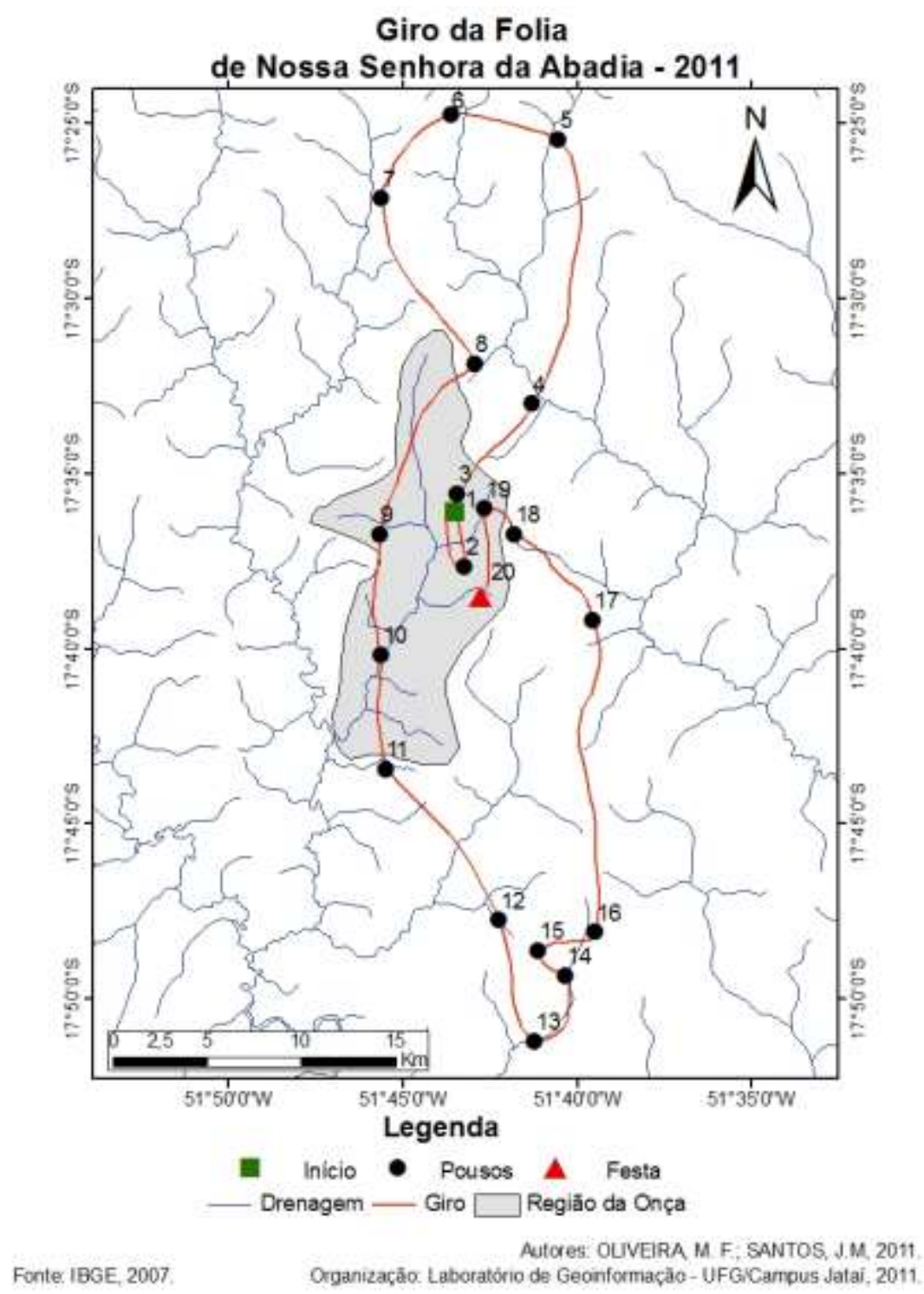

Fonte: Oliveira, M. F. (2012).

Para Oliveira (2012, p. 36) o mapa 01, apresenta a "Região da Onça", bem como o da folia de forma concreta e simbólica. O giro da folia percorre todos os anos praticamente o mesmo percurso, mas, muda seu sentido dependendo da localização da casa do festeiro.

O território sagrado criado pela folia é reforçado no seu tempo pelas vivências dos moradores visitados, pelos participantes e pelos próprios foliões. O valor simbólico acrescentado ao lugar que pelo giro foi produzido, é cada vez mais aceito e envolvido de emoções, o que garante no próximo ano o desenvolvimento e continuidade das práticas religiosas. Dessa forma, o lugar passa atrair comportamentos religiosos, como a peregrinação e romarias dos fiéis, no tempo da folia. Esses elementos conferem à territorialidade da folia um reforço ao seu empenho, que é angariar esmolas, mobilizar e garantir a presença dos fiéis durante o pagamento da promessa inicial à santa. 
Em acordo com Haesbaert (2009, p. 107) a pretensão é demonstrar o que seria a dinâmica da territorialidade da fé neste lugar pelas práticas sociais.

é através das problemáticas envolvidas nos processos de territorialização (ao mesmo tempo materiais e simbólicos) que podemos compreender - e, minimamente, definir - não exatamente "o que é" o território, mas dilemas/ações que, em/através de seu nome, são empreendidos.

No entanto, o trabalho empírico e o mapa 01 de Oliveira (2012) nos permite observar que territorialidade da festa profano/sagrada, vai além do que o os moradores/devotos consideram por "Região da Onça". Para os moradores a festa envolve toda a "Região da Onça" - no mapa o recorte central na cor cinza. Mas, o trajeto do giro da folia de 2011, nos mostra que a territorialidade da folia abrange uma dimensão espacial maior. Inclusive o ponto 05 visitado, extrapola o limite fronteiriço entre Jatai e Rio Verde/GO. Ou seja, ele está no município de Rio Verde/GO. E o ponto 13 situa se próximo ao perímetro urbano de Jataí/GO. Oliveira (2012, p. 37) afirma que:

a festa dedicada a santa mobiliza uma dimensão espacial considerável muito além dos adeptos da região. Vale dizer que ela sempre atraiu sujeitos de outros lugares da zona rural e, inclusive, da zona urbana.

Os processos da territorialidade da folia e da festa acontecem de modo que os elementos constituintes dos eventos revelem os acontecimentos visíveis e invisíveis, bem como os tangíveis e intangíveis. Para Almeida (2013, p. 45) "a invisibilidade é o resultado de um processo complexo no qual confluem a mobilidade, a volatilidade, as fusões, a multiplicação das realidades inéditas, as alianças insólitas". Dessa forma, por meio de nossas percepções nos conectamos nos símbolos objetivos, de forma a evidenciar a subjetividade que eles expressam. Almeida (2013, p. 45) assegura que pela percepção é possível:

Argumentar em favor do fato de a realidade estar constituída, simultaneamente, por presenças e ausências, por elementos que se manifestam e por outros que se escondem, porém continuam presentes. Breve, a realidade não é apenas o que se vê.

No mesmo enfoque de Almeida (2013), Bonnemaison (2002, p. 103) havia afirmado que:

tanto quanto possível os geógrafos devem procurar compreender a concepção de mundo que existe no coração do grupo ou da sociedade que 
estejam estudando. Trata-se aí de reencontrar os lugares onde se exprime a cultura e, depois, a espécie de relação secreta e emocional que liga os homens e sua terra e, no mesmo movimento, funda sua identidade cultural.

Alguns dos elementos simbólicos são percebidos, por meio dos sentimentos durante os momentos de atuação do sagrado e do profano e nos revelam pelas ações e linguagens corporais, as intangibilidades e as invisibilidades contidas neles. No entanto, os afetos e a fé são materializados por meio dos gestos dos devotos ao beijar, tocar e colocar objetos ou dinheiro na bandeira, ao seguir ajoelhado junto à folia, ao andar descalço, ao usar roupas brancas pagando promessas. Também, pela emoção e expressão corporal ao rezar, numa relação íntima com Deus, pela emoção ao construir cuidadosamente o altar, na inserção de objetos no altar pelos devotos no decorrer da festa como velas e flores. O próprio ato de realizar e participar da festa pelos devotos concretiza também a fé, desse modo o giro da folia ao mesmo tempo, pode ser considerado como um ato de fé, no qual se tem o encontro com a santa, materializando e reforçando assim sua simbologia na espacialidade.

A folia é um evento importante que ajuda a compor a festa em questão. No entanto, seu intuito é mobilizar a comunidade para celebração em homenagem a santa, arrecadar doações ou esmolas para ajudar o festeiro custear a festa. No tempo sagrado a folia se empenha em levar a bandeira da santa por todo o trajeto, rezar e cantar nas residências juntamente com os moradores e com alguns devotos participantes. Em alguns momentos os devotos fazem da folia ocasião para pagar promessas. A folia de Nossa Senhora da Abadia aqui é compreendia como vários outros grupos de foliões pelo país, sendo, um "grupo precatório de cantores e de instrumentistas, seguidos de acompanhantes e viajores rituais, entre casas de moradores rurais durante um período anual de festejos" (BRANDÃO, 2004, p. 347).

A folia é constituída hierarquicamente pelo chefe, o alfer, o garrucheiro e os foliões. $\mathrm{O}$ chefe tem a função de liderar o grupo, organizar o giro, e conduzir a peregrinação. $\mathrm{O}$ alfer tem a responsabilidade de carregar a bandeira da santa durante o giro, de recolher os donativos, bem como os votos de alguns devotos. A função do garrucheiro é avisar por meio de tiros de garrucha a chegada da folia às residências. Os demais foliões geralmente são cantores e instrumentistas. Nesta organização da folia percebe se a relação de poder que é uma característica constituinte do território. Assim os elementos, os eventos as representações são organizadas por uma forma de poder, seja na folia e na própria festa. Isso pode ser comprovado conforme Gomes (2005, p. 37): 
O que transforma uma área ou um espaço em território é a maneira pela qual essa ordem espacial serve como um instrumento essencial a quem exerce o controle sobre as outras pessoas.

Em acordo com as ideias deste autor, analisando a constituição da folia e, pela forma que exerce sua função na "Região da Onça", é visível a relação de poder da religiosidade popular sobre o território. Por meio do giro, ela assegura a adesão dos fiéis à tradição bem como a sua participação no dia da festa.

\section{Folia - momento de exercer a fé}

Os moradores devotos fazem questão da folia em suas casas, para se ter em seu interior a imagem da santa (bandeira) acreditando em suas bênçãos, para rezarem o terço, oferecer esmolas e pagar promessas. Dessa forma, o ritual mantém a proximidade com a padroeira e consolida o sentido religioso aos devotos assegurando assim a prática da religiosidade popular, do sagrado e da fé. Conforme Rosendahl (2010, p.195):

A religião só se mantém se sua territorialidade for preservada e, neste sentido, pode-se acrescentar que é pela existência de uma religião que se cria um território e é pelo território que se fortalecem as experiências religiosas coletivas ou individuais.

A respeito dessa territorialidade que a folia cria durante o giro na região, consideramos o que Rosendahl (2010, p. 187) classifica como "territorialidades religiosas ou quase sagradas". De forma que a territorialidade religiosa aqui instituída pela folia reforça a tradição que por sua vez é carregada de signos e significados. A territorialidade se fixa por meio da mobilidade da folia e da santa (bandeira), e o enraizamento material e simbólico estabelece uma relação entre o sagrado e profano dentro deste espaço-território. O simbolismo contido na territorialidade durante o giro da folia, constrói o espaço subjetivo por meio das vivências, do sentimento de pertencimento, da identidade religiosa e cultural, durante o tempo da festa.

Mas, este espaço subjetivo e materializado mesmo por tempo determinado é composto por momentos de harmonias e de tensões. As tensões ocorrem em poucas ocasiões, quando a folia não é bem recebida pelo morador, por diversos motivos entre eles, religiosos, 
por preconceitos ou por indelicadezas. Os foliões dizem não responder às provocações ocorridas nestes momentos, eles agradecem a atenção e vão à procura de outro morador.

Em relação aos movimentos constituintes do território Saquet $(2005$, p. 52) aponta que:

o território funda-se em relações e conflitos, contradições, e é substantivado, simultaneamente, pela unidade. Há, ao mesmo tempo, em sua composição, diversidade unidade, heterogeneidade e homogeneidade, desigualdades e diferenças. Essas contradições condicionam o movimento interior e exterior ao território. Negligenciá-las significa negar o movimento e as interações. Não se trata claro, de entendê-las como simples pares, mas como multiformes.

No momento do conflito a territorialidade do sagrado sofre uma suspensão no movimento, ou seja, há uma negação da efetividade da reciprocidade simbólica e concreta naquele lugar. Mas, esse indeferimento não significa uma quebra do objetivo do giro da folia. Isso é um acontecimento anunciado e não enfraquece o movimento dentro do território, e a superação acontece na continuidade da manifestação. Mas, quando há harmonia entre os moradores visitados e a folia, a vivência reforça e valoriza a tradição do giro com seus signos e ritos. Na opinião de Bonnemaison (2002, p. 111):

Os símbolos ganham maior força e realce quando se encarnam em lugares. $\mathrm{O}$ espaço cultural é um espaço geossimbólico, carregado de efetividade e significações: em sua expressão mais forte, torna-se território-santuário, isto é, um espaço de comunhão com um conjunto de signos e de valores. A ideia de território fica então associada a ideia de conservação cultural.

Nessa ideia de conservação cultural, a prática social fixa no espaço geográfico um movimento próprio, que inscreve seus símbolos e sua organização social. E a comunidade envolvida consegue pela vivência descodificar as dimensões culturais desse território, vigorando assim a relação simbólica da tradição. O grupo beneficia dessa espacialidade para praticar sua fé e reforçar sua identidade cultural e religiosa. Produz dessa forma, uma territorialidade religiosa, que para Rosendahl (2010, p. 195) significa "o conjunto de práticas desenvolvido por instituições ou grupos no sentido de controlar um dado território".

\section{Identidade um processo de coesões}

Saquet (2005, p. 52) traz outro elemento importante e constituinte do território - a identidade. Para o autor "sem contradição e movimento não há território, não há identidade". 
E a identidade é um "produto de interações reciprocas, de relações no âmbito da E-P-C-N". E que "a concomitância do ser e do não ser" no território o institui, e cria condições de realizar as relações sociais sendo elas conflituosas/harmoniosas. Neste entendimento, Almeida (2009, p. 101) acrescenta que em relação ao território "contemporaneamente ele é parte e produto de diversos grupos e categorias de indivíduos e todos tem uma legitimidade distinta ao se apropriar dele de uma forma ou de outra". No entanto o ser e o não ser, no território se completam por conter no seu tempo, história e vivências, ou seja, o território é heterogêneo e permite por meio das relações e práticas, a formação das identidades.

O território percebido durante o tempo da festa de Nossa Senhora da Abadia, comporta a vivência, afetividade, atividade religiosa e a identidade de seus devotos. Esses elementos transmitem energias para que a comunidade por meio do sentimento de pertencimento encontre sua identidade. E dessa forma a identidade afirmada, a comunidade unida e envolvida alcança o objetivo comum a todos da manifestação, que é manter a tradição de pagar o voto a santa. Para tanto, desenvolvem os eventos da festa, realizam a reciprocidade entre os participantes, consequentemente acontecem as relações sociais, e esses resultam na identidade cultural, religiosa e territorial do grupo formada pela composição simbólica.

Na linha de pensamento de Saquet (2005), Cruz (2007, p. 15) também aponta que a identidade "é sempre uma construção histórica e relacional dos significados sociais e culturais que norteiam o processo de distinção e identificação de um indivíduo ou de grupo". No entanto, para Cruz (2007, p. 15), a identidade está em construção permanente, "neste sentido a identidade é dinâmica, múltipla, aberta e contingente". Nesta perspectiva da dinamicidade da identidade Giménez (2000, p. 117) aponta que "La identidad es creatividad permanente y exploración continua, y en cuanto tal implica una dialéctica de continuidad y cambio". Encontramos em Penna (1992, p. 72) as relações sociais como constituinte da identidade, e outro elemento importante, ao seu significado são as memorialidades, no entanto agrega importância ao

papel da memória enquanto suporte de identidade: quer em nível individual quer coletivo, ela seleciona informações, conhecimentos e experiências, articulando de forma inteligível (dando-lhes significado e valor) os aspectos multiformes do vivido.

No entanto as identidades religiosa, cultural e territorial identificadas no território em questão foram, serão e estão em construção historicamente no processo de realizações das práticas sociais, pelas memorialidades, tradição e conflitos. Em relação à construção da 
identidade Castells (1999, p. 23) defende que ela surge a partir da "matéria-prima fornecida pela história, geografia, biologia, instituições produtivas e reprodutivas, pela memória coletiva e por fantasias pessoais, pelos aparatos de poder e revelações de cunho religioso." Compartilha dessa ideia também Almeida (2005, p. 109) ao dizer que "a identidade pode conter, forma combinada, elementos históricos, projetados e patrimoniais". No entanto a identidade ao surgir das relações sociais cria elementos significativos para sua existência, conforme sua temporalidade. Vale lembrar que a festa de Nossa Senhora da Abadia surgiu por meio de conflitos na região, como já descrito no texto.

Quando ocorrem tensões durante o giro da folia e durante a realização da festa, os participantes/devotos ficam preocupados principalmente em relação a continuidade da festa. Preocupam-se com a força dos conflitos sobre a manifestação. Ou seja, no caso de o giro perder um ponto naquele momento, e no caso da festa a falta de respeito com o momento sagrado e profano, que eventualmente pode causar um desgaste simbólico/material. Durante esse processo das relações conflituosas ou não conflituosa que a identidade se firma ou se rompe. De modo que são nestes momentos que os indivíduos são selecionados, considerados ou desconsiderados como membros do grupo que empunham a tradição. Cruz (2007, p. 18) considera que:

é nesse jogo relacional de classificação/distinção/identificação que a identidade é construída e configurada ao mesmo tempo como inclusão e exclusão: ela identifica o grupo (membros do grupo que são idênticos) e os distingue dos outros grupos (cujos membros são diferentes dos primeiros sob um certo ponto de vista).

Torna se considerável a compreensão das diferenças dentro desse campo de relações sociais, porque a diferença se torna um processo de conhecer/respeitar o outro, que nesse caso é o "diferente". Ou seja, o outro pensa/age diferente do grupo em evidência, considerando que estão se relacionando e formando as identidades. Neste universo do fazer e saber festivo bem como suas representações simbólicas dão ao participante/devoto e ao "diferente" o poder de expressar suas diversas autonomias (religiosa, cultural, social e política). Dessa forma, as atitudes pessoais vão posicionar e legitimar os sujeitos em suas identidades dentro do grupo.

Sobre a constituição da identidade, DaMatta (2000, p. 17) também afirma que, a "construção de uma identidade [...] é feita de afirmativas e de negativas diante de certas questões". E este manifesto centenário vai acentuando suas características e suas especificidades elaborando o seu sentido. 
Ao assegurar as identidades o grupo se sente seguro para realizar o festejo bem como seus símbolos e ritos tradicionais, diante dessa consideração, Cruz (2007, p. 20) acredita que “a eficácia das estratégias indenitárias e o seu poder de legitimação irão depender da situação de cada grupo no jogo do poder". Na festa de Nossa Senhora da Abadia, a relação de poder em questão é evidenciada pelos elementos simbólicos e políticos hegemonicamente presentes em sua estrutura social. Reforça se assim que a identidade, também, é um produto das relações sociais em um determinado recorte do tempo/espaço geográfico.

Em acordo com Cruz (2007, p. 23) sobre as identidades territoriais, Pollice (2010, p. 8-9) aborda que a identidade territorial "nasce do processo autorreferencial colocado em ação por uma comunidade que se apropria culturalmente de um âmbito espacial predefinido". Ou seja, no caso em estudo são pelas relações sociais durante a territorialização da festa que se cria a identidade territorial.

As percepções apontadas no manifesto cultural na Região da Onça sobre as identidades cultural, religiosa e territorial, interpretadas conforme Penna (1992, p. 51) "tornam a identidade numa perspectiva empírica, como algo dado, vale dizer, diretamente decorrente de algum fator observável". As identidades apontadas na festa têm a intenção de evidencia-las no seu processo de formação e de estabilidade na espacialidade em que se concebe. Ressalto que este estudo não se encontra acabado, se faz necessário em outros momentos aprofundar e examinar ainda mais sobre o assunto.

\section{Considerações finais}

A festa de Nossa Senhora da Abadia é uma festa popular que permite ser recriada e apropriada a cada momento no seu tempo, pelas relações sociais e consequentemente pelas múltiplas identidades e territorialidades apreendidas. Isso resulta num produto social, concebido por elementos próprios da manifestação cultural como o simbolismo (visível/invisível/intangível), rituais e sua própria política. Esta festa também pode ser considerada uma resistência da cultura tradicional, num território abarcado pelas técnicas modernas inseridas no espaço que ela se realiza - no espaço das tecnologias modernas do espaço rural, como agricultura, pecuária e pelo setor sucroenergético. Ou seja, por meio das relações sociais de parentesco, compadrio e amizade, dos saberes, dos fazeres, da religiosidade rústica e das reciprocidades, a festa se assegura pelas identidades, resultado das diferenças no território. 
O território onde a festa se realiza também é um espaço das relações sociais de poder, no qual se tem em seu contexto histórico, econômico e cultural as contradições e desigualdades de seus participantes durante o tempo de sua comemoração. Mas, a festa de Nossa Senhora da Abadia é o resultado da luta em afirmação a sua representatividade cultural de símbolos materiais e imateriais. Além de sua religiosidade lhe servir como processo de integração das suas diversas identidades.

\section{Referências}

AMARAL, R. de C. de M. P. Festa à Brasileira - significados do festejar, no país que "não é sério". São Paulo, SP: 1998. 287 f. Originalmente apresentada como tese de doutorado, Faculdade de Filosofia, Letras e Ciências Humanas da Universidade de São Paulo. 1998. Disponível em: <http:/www.teses.usp.br/teses/disponiveis/8/8134/tde-21102004-134208/ptbr.php>. Acesso em 11 mar. 2011.

ALMEIDA, M. G. de. Fronteiras, territórios e territorialidades. Revista da ANPEGE. Fortaleza, 2005. Ano 2, n. 2. p. 103-114.

ALMEIDA, M. G. de. Diásporas: viver entre-territórios e entre-culturas? In: SAQUET, M. A.; SPOSITO, E. S. (Orgs). Territórios e territorialidades: Teorias, processos e conflitos. São Paulo: Expressão Popular, 2009. p. 175-195.

ALMEIDA, M. G. A Propósito do trato do invisível, do intangível e do discurso na Geografia Cultural. ANPEGE. Fortaleza, jan/jun. 2013. v. 9, n. 11, p. 41-50.

BONNEMAISON, J. Viagem em torno do território. In: Correa R. L.; ROSENDAHL, Z.

Geografia cultural: um Século (III). Rio de Janeiro: Ed. UERJ, 2002. p. 83-131.

BRANDÃO, C. R. De tão longe venho vindo: símbolos, gestos e rituais do catolicismo popular em Goiás. Goiânia: UFG, 2004. 412 p.

CASTELLS, M. O poder da identidade. Tradução: Klauss Brandini Gerhardt.

São Paulo: Paz e Terra,1999. p. 21-92. 2.v.

CRUZ, V. C. Itinerários teóricos sobre a relação entre território e identidade. In: BEZERRA,

A. C. A. et. Al. (Orgs). Itinerários Geográficos. Niterói. EdUFF, 2007. p. 13-35.

DAMATTA, R. O que faz o brasil Brasil? Rio de Janeiro: Rocco. 2000. p. 09-20.

GIMÉNEZ, G. Território, Culturas e identidades. La regiòn sociocultural. In.

BARBERO, J. M. et. al. (Eds.). Cultura y región. Colombia: Litocamargo. 2000, p. 87-132.

GOMES, P.C. da C. Sobre Territórios, Escalas e Responsabilidade. In: HEIDRICH, A. L. et.al. (Orgs). A Emergência Multiterritorialidade: A ressignificação da relação do humano com o espaço. Porto Alegre: Editora da UFRGS, 2005. p. 37-45.

HAESBAERT, R. Dilemas de conceitos: Espaço-território e Contenção Territorial. In:

SAQUET, M. A; SPOSITO, E. S. (Orgs.). Territórios e Territorialidades: Teorias,

Processos e Conflitos. São Paulo: Expressão Popular, 2009. p. 95-120.

HALL, S. A identidade Cultural na Pós-Modernidade. 11 ed. Tradução: Tomaz Tadeu da Silva e Guacira Lopes Lobo. Rio de Janeiro: DP\&A, 1997. p. 07-23.

MACHADO, M. C. T. Cultura popular: um contínuo refazer de práticas e representações. In: PATRIOTA, R.; RAMOS, A. F. (Orgs). História e Cultura: espaços plurais. Uberlândia: Asppectus, 2002. p. 335-345.

MAIA, Carlos Eduardo Santos. Ensaio interpretativo da dimensão espacial das festas populares proposições sobre festas brasileiras. In: CORRÊA, R. L.; ROSENDAHL, Z. 
(Orgs.). Manifestação da cultura no espaço. 1. ed. Rio de Janeiro: EDUERJ, 1999. p.191218.

MUÑOZ, F. El Tiempo del territorio, los territorios del tiempo. In: NOGUÉ, J;

ROMERO, J. (Eds.). Las otras geografías. Valencia: Tirant lo Blanch, 2006. p. 235-254.

ROSENDAHL, Z. Hierópolis e catolicismo popular brasileiro: uma possível tipologia. In:

ROSENDAHL, Z. Espaço e religião: uma abordagem geográfica. 2. ed. EDUERJ, 2002. p.

71-80.

ROSENDAHL, Z. Espaço sagrado: exemplo de Porto das Caixas, Baixada Fluminense. In:

ROSENDAHL, Z. Hierópolis: o sagrado e o urbano. 2. ed. EDUERJ, 2009. p. 55-76.

ROSENDAHL, Zeny. Espaço, cultura e religião. In: CORREAA, R. L.; ROSENDAHL, Z.

(Orgs.). Introdução à geografia cultural. 3. Ed. Rio de Janeiro: Bertrand Brasil, 2010. 226

p.

OLIVEIRA, M. F. O giro de um povo: o espaço/tempo da festa de Nossa Senhora da Abadia em Jataí-GO. Jataí, GO: 2012. 125p. Originalmente apresentada como dissertação de mestrado, Universidade Federal de Goiás. 2012.

SAQUET, M. A. A abordagem territorial: considerações sobre a dialética do pensamento e do território. In: HEIDRICH, A. L. et al (Orgs). A emergência da Multiterritorialidade: a ressignificação da relação do humano com o espaço. Porto Alegre: Editora da UFRGS, 2005. p. $47-60$

SILVA, W. F. da. O avanço do setor sucroenergético no Cerrado: os impactos da expansão canavieira na dinâmica socioespacial de Jataí (GO). Jataí, GO: 2011. 228p. Originalmente apresentada como dissertação de mestrado, Universidade Federal de Goiás. 2011.

PENNA, M. O que faz ser nordestino: identidades sociais, interesses e o "escândalo" Erundina. São Paulo: Cortez, 1992.

POLLICE, F. O papel da identidade territorial no desenvolvimento local. Espaço e Cultura. UERJ, RJ, n. 27, p. 7-23, jan-jun, 2010. 